\title{
Domains of Colloidal Size Mediated by Self Assembly of Small Molecules in a Polymer Matrix: a Three-Level Hierarchy of Assembly
}

Bindu Tuteja, Mohammad Moniruzzaman and Pudupadi R. Sundararajan*

\section{Experimental}

The synthesis and purification procedures for carbamates have been described before ${ }^{12}$ We identify the carbamates as $\mathrm{C}_{\mathrm{x}}$, which stands for the carbamate having $\mathrm{x}$ number of carbon atoms at the alkyl side chain derived from alcohol.

Chloroform was used to prepare the blends of BPAPC and carbamate since the carbamates have very little solubility in most other solvents. For most of the experiments $0.5,1,3,5,10$ and 15 wt- $\%$ of carbamate in BPAPC was used. Our previous study ${ }^{12}$ on these carbamates showed that when two carbamates are blended at different compositions, it causes a reduction in the crystallinity, crystallite and spherulite sizes and heat of fusion of the carbamates. Hence a $90 / 10$ blend of two carbamates $\left(\mathrm{C}_{12} / \mathrm{C}_{16}\right)$ was also used in this study to blend with the polycarbonate. Homologous blend of $\mathrm{C}_{12} / \mathrm{C}_{16}$ was prepared first by melt mixing. A pre-weighed mixture of $\mathrm{C}_{12}$ and $\mathrm{C}_{16}$ was heated in a 10 $\mathrm{ml}$ beaker at $120^{\circ} \mathrm{C}$ with continuous stirring. After 1 hour, the melt was slowly cooled at room temperature.

To make solvent cast films, BPAPC and the carbamate (or the blends of carbamates) were dissolved in chloroform of laboratory grade at room temperature to form a solution of $\sim 10 \% \mathrm{w} / \mathrm{v}$ concentration. The films were cast on a silanized glass plate using an aluminum spreader. They were dried at room temperature for 48 hours, followed by drying for 24 hours under vacuum. The films were kept at room temperature for a few weeks to make sure all the solvent has evaporated. The final thickness of the films was about $25 \mu \mathrm{m}$, as determined by Scanning Electron Microscopy.

The solutions of BPAPC and the carbamates were transparent up to a certain wt $\%$ of the carbamates, after which the carbamate is either insoluble or forms colloidal suspension in the BPAPC solution. The $\mathrm{C}_{7}, \mathrm{C}_{8}$ and $\mathrm{C}_{12}$ form transparent solutions up to 5 -wt $\%$ of the 
carbamates, but colloidal suspension with 10 and 15 -wt $\%$. Interestingly, while $\mathrm{C}_{16}$ does not dissolve well beyond 5-wt $\%, \mathrm{C}_{12} / \mathrm{C}_{16}$ blend shows solubility in BPAPC solution: the solution was transparent up to $10-\mathrm{wt} \%$ and it shows colloidal suspension at $15-\mathrm{wt} \%$ of the carbamate blend.

Thermal analysis was carried out using TA instrument $2010 \mathrm{DSC}$ at heating rate of $10{ }^{\circ} \mathrm{C}$ $\min ^{-1}$.The instrument was calibrated for temperature and energy with indium and tin references samples. DSC traces were recorded with about 7-10 $\mathrm{mg}$ of sample in nitrogen atmosphere. A Zeiss Axioplan 2 imaging universal optical microscope with Q-imaging Retiga digital camera was used to record the optical micrographs. Northern Eclipse (version 6.0) image processing software was used to capture the images as well as to calculate the domain area and spherulite radius. 